\title{
SAFETY-ORIENTED MULTI-TASK APPROACH TO MANAGE WHOLE-BODY VIBRATION EXPOSURE AMONG QUARRY OPERATORS
}

\author{
GUIDO ALFARO DEGAN ${ }^{1}$, ANDRE ANTONUCCI $^{2}$, GIANLUCA COLTRINARI ${ }^{1} \&$ DARIO LIPPIELLO \\ ${ }^{1}$ Department of Engineering, University of Roma Tre, Italy \\ ${ }^{2}$ University of Chieti G. d'Annunzio, Italy
}

\begin{abstract}
The oscillation generated by external and internal forces is one of the principal characteristics of machinery. The impulses are transmitted to workers' bodies through the part in contact with the vibrational surface, such as the steering wheel of a machine (known as "hand arm vibration" (HAV)), contact surface or the driver's seat of a machine (known as "whole-body vibration" (WBV)). These represent an occupational issue that can generate adverse health effects, annoyance or simple discomfort for the workers during their daily activities. Biodynamic responses of the human body to WBV are reported in terms of the driving point mechanical impedance and apparent mass, transmissibility and the power absorbed by the body. The most common WBV occupational exposure is represented by the operator seated in a variety of vehicle categories such as cars, buses, forklifts, tractors, trucks, and heavy machinery either on or off paved roads in different work contexts. Previous studies investigated the power absorbed by the human body during daily exposure and the consequent potential negative effects on the human health. They evidenced that health effects are connected to the intensity of the vibration levels. In order to reduce workers' exposure, an efficient method could consist of analysing the power frequency spectrum. In fact it provides relevant indications in order to adopt the correct preventative or corrective measurements such as specific suspended seats, extra breaks and individual work schedules. This study is aimed at assessing the WBV exposure among drivers of machinery in a quarrying context thus proving a useful tool to manage such a risk in terms of work organization and scheduling.
\end{abstract}

Keywords: whole-body vibration, quarrying activities, working task organization, earth moving machinery.

\section{INTRODUCTION}

Whole-body vibration (WBV) may generate different effects depending on the characteristics of the physical agent itself. Exposure to such an agent may, in fact, generate adverse effects on human health [1] but, in the opposite way, it may induce a good response in the rehabilitation of some chronic diseases as well as for muscle enhancement [2]. However the most common effect is recorded in the field of occupational safety where it represents a risk factor that may affect operators such as drivers of fork-lift trucks [3], tractors [4], loaders [5], LHD vehicles [6]. It's widely recognized that long term exposure to high amplitude WBV is strongly linked to the subsequent development of a particular stress for the human body and back disease has been shown as a connected effect [7]. This last may be influenced with many factors, such as time exposure to the driving task [8], wrong posture [9] or other related factors such as performing manual handling as part of the task during the daily activities [10]. These health problems are very relevant in many workplaces; for example the musculoskeletal disorders (MSDs) accounted for 32\% of all injuries and illnesses in 2014 among full-time quarry operators [11], [12]. An accurate risk assessment procedure, based on standards or established norms, should be carried out in order to prevent the negative health outcomes associated with WBV exposure. The most widely accepted standards for measurement and evaluation of human exposure to WBV are the ISO 2631-1 report and the 
European Union Directive 2002/44/EC [13]. These norms define specific methods to assess frequency-weighted acceleration amplitude. The use of a method rather than another one is being discussed by many researchers also in the quarry sector [14], [15]. In fact after the publication of ISO 2631-5:2004, both ISO 2631-1:1997 and ISO 2631-5:2004 were utilised simultaneously in research works to assess occupational risks [16]. This feature caused the discussion about the health guidance caution zones (HGCZs) in these two standards. Many researchers have studied these problems regarding of the employment of various vehicles in the quarry activities with particular attention to haul trucks because of their extensive use in the surface mining industry [17]. Even if the reduced number of field tests prevents any strong conclusion, it appears that the different phases of the LHD (Load-Haul-Dump) cycle are different in terms of effects induced among workers [18]. Moreover vibration amplitudes were greatest in the vertical direction, and particular while the trucks were driven unloaded. Another relevant aspect is clearly connected with the sample duration. Eger et al. [19] collected one hour duration WBV measurements from eight haul trucks of varying capacities (30-150 ton) during normal operation at surface mines in Northern Ontario. Seven of the eight measurements were found to lie within the HGCZ defined by ISO2631.1 for r.m.s. and all eight VDV measurements lay within the HGCZ. There is limited evidence to suggest that haul trucks used in surface mining may expose operators to levels of WBV which are associated with risks to the operators' health, however there is some inconsistency in previous reports. These differences are likely to arise from the short measurement durations associated with some of the previous investigations, as well as variability in equipment and sites. During the exposure to the WBV, a driver can be exposed to particular mechanical stress on the body due to vibration peaks. These can be generated by many factors, for example the ground conditions, the vehicle speed and wear degree of the seat. The vehicle constitutes the source vibration and the primary contact point for transmission of vertical WBV to drivers is through vehicle seat (amplifies or attenuates vibration at the base) [20]. Seating system plays a vital role in isolating the vibration. In order to obtain the vibration attenuation, this target may be achieved at different levels. The first one concerns the source vibration, the vehicle. Some wheel loaders employed in the quarry sites are equipped with ride control systems which reduce the vehicle pitching motion [18] and thereby reduce the fore-and-aft vibration exposure, although no study has been made to quantify their efficiency. Sure enough hydropneumatic suspensions (HPS), owing to their compact design and superior design flexibility, are increasingly being implemented in commercial road and off-road vehicles [21]. Their nonlinear pneumatic-stiffness and hydraulic-damping properties could provide enhanced attenuation of ride vibrations under large payload variations, while offering improved handling performance through cross-axle interconnections or control interventions. The variations in fluid compressibility and free gas volume cause increase in effective stiffness but considerable reduction in the damping in a highly nonlinear manner. Increasing the gas volume fraction resulted in substantial hysteresis in the force-deflection and force-velocity characteristics of the strut. The second level at which attenuation occurs is at the seat level that represents the contact point between the driver and the vehicle. Although fore-and-aft suspended seats are available on the market, most of the wheel loaders are equipped with seats without suspension in the fore-and-aft direction. The predicting the responses of the combined human body and seat structural responses to the vibration generate by the vehicle is still challenging. This is mainly due to the nonlinearity and complexity of the human body dynamics. Therefore, alternative methods are required to characterize the dynamics of the combined human body-seat structure. A few studies developed methods on the basis of multi-body simulation to reduce the WBV on bigger wheel loaders. This work introduced an automatic simulation process, which was developed based on a full-vehicle model of a wheel 
loader. With this automatic simulation process, axle and cab suspensions on the wheel loader can be optimized for more riding comfort and operational safety. Other researchers, through help of multi-body models of a wheel loader with suspended axles or unsuspended axles, investigated that WBV in the vertical and the longitudinal directions on the wheel loader was reduced greatly by suspended axles [22]. It's important to highlight that than the education of the drivers has a relevant role in order to prevent the negative effects. The WBV exposure was measured on two different backhoe loaders before and after the operators got an education on eco-driving and vibration avoidance. This training has shown positive results for the purpose of reduce the WBV on backhoe loaders efficiently [23]. The present work is based on a measurement campaign for drivers of haul trucks during a range of normal operating conditions in a basalt quarry site. The aim of the current investigation is to examine the variation of WBV exposures on two different vehicles, one model designed in order to be employed only in the quarry site, the other one, can represent a useful option if employed in different working activities. Once the characteristics of the physical agent have been defined, a safety-oriented organization of working task may be carried out with the focus of reducing WBV exposure by means of different vehicle adoption without determining loss of productivity.

\section{MATERIALS AND METHODS}

The WBV measurements were taken from two different haul trucks during the LHD activities into a basalt quarry near Rome. The trucks employed in the measurement campaign ranged in capacity from 32 to 80 tonnes. The haul trucks were conducted by two different drivers with similar physical characteristics and they agreed to participate to the tests. Their data are reported in Table 1.

Table 1: Driver's characteristics.

\begin{tabular}{|l|c|c|c|c|}
\hline & Age (years) & Weight $(\mathrm{kg})$ & Height $(\mathrm{cm})$ & $\begin{array}{c}\text { Driver's experience } \\
\text { (years) }\end{array}$ \\
\hline Driver 1 & 34 & 75 & 173 & 10 \\
\hline Driver 2 & 40 & 110 & 185 & 1 \\
\hline
\end{tabular}

Field tests of vibration measurements were carried out on two different vehicles: Dumper 769 Caterpillar and Mercedes Actros (see Fig. 1). The characteristics of the vehicles are reported in Table 2.

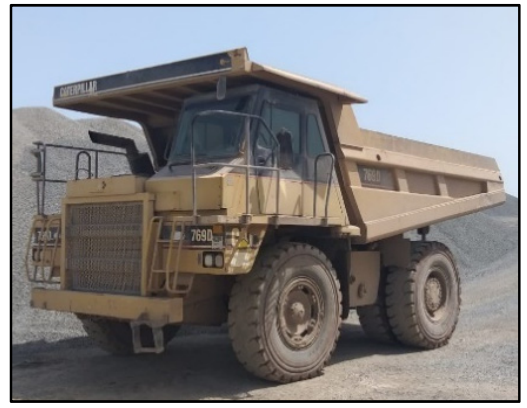

(a)

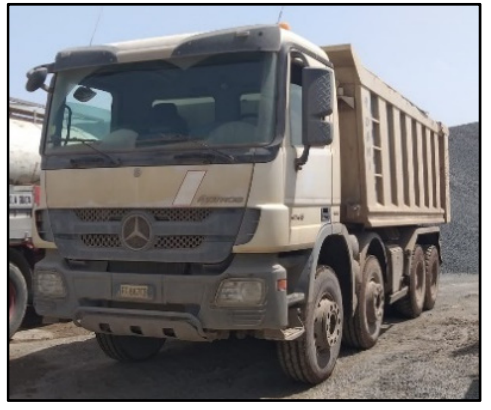

(b)

Figure 1: (a) 769 Caterpillar model; and (b) Mercedes model. 
Table 2: Vehicle's characteristics.

\begin{tabular}{|l|c|c|c|c|}
\hline & $\begin{array}{c}\text { Weight empty } \\
\text { configuration (ton) }\end{array}$ & $\begin{array}{c}\text { Full weight } \\
\text { configuration (ton) }\end{array}$ & $\begin{array}{c}\text { Max speed } \\
(\mathrm{km})\end{array}$ & Year \\
\hline Dumper 769 & 45 & 80 & 80 & 2006 \\
\hline Mercedes & 15 & 32 & 130 & 2010 \\
\hline
\end{tabular}

Each vehicle is furnished of a seat suspension in the vertical direction comprised of a passive air spring and an inclined hydraulic shock absorber. Instead the driver's seat does not have any suspension in the longitudinal and the lateral directions. The acceleration measurements in the vehicles were realized on the surface and at the base of the drivers' seats in the same roadway conditions inside the quarry site. The test route had a length of $350 \mathrm{~m}$ with different sections: for haulage and dump phases were made up of rock smooth surface, with an $8-10^{\circ}$ slanting and a rough gravel zone near the load point while (see Fig. 2). The weather was in sunny dry conditions all time long during the summer months and typical temperatures were approximately $27 \pm 3^{\circ} \mathrm{C}$. The speed of the vehicles ranged from $10-25 \mathrm{~km} / \mathrm{h}$, by reason of the automatic transmission system that modified the engine rpm of the truck and consequently the input source signal. WBV exposure were measured according to the standard procedure of the ISO 2631-1 (1997) guidelines.

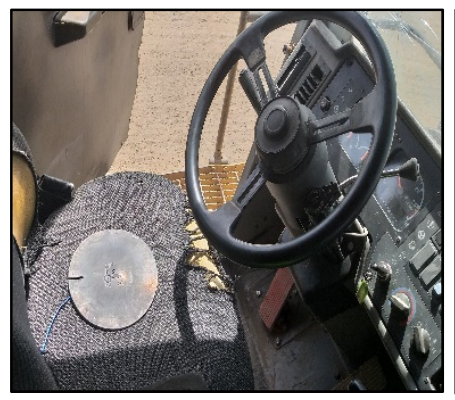

(a)

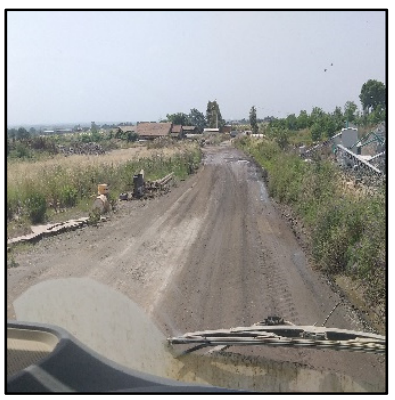

(b)

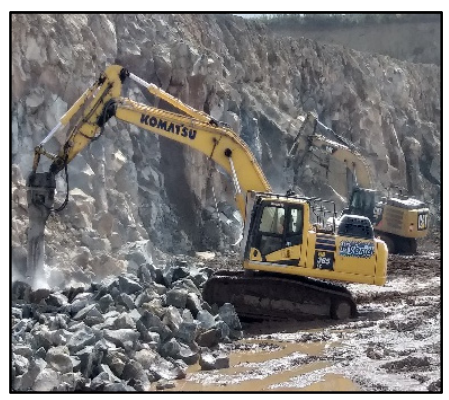

(c)

Figure 2: (a) Transducer positioning on the driver's seat; (b) Test route inside the quarry site; and (c) Load operation.

A tri-axial seat pad accelerometer (PCB393) was placed on the driver's seat of the truck with regards to direction and anatomical positioning (see Fig. 2). Vibration was measured in a three-axis coordinate system $(x, y$ and $z)$ in order to evaluate the entry points of vibration in worker's body: the $x$-axis to measure vibration in the anterior-posterior direction, the $y$ axis in the medial-lateral direction, and the $z$-axis in the vertical direction. In order to characterize the signal source vibration a uniaxial accelerometer (PCB 393A03) was attached on both vehicles through permanent magnet at the base of the seat. All the accelerometers were connected on three different channels to Soundbook system and the signal was acquired through Samurai software at the sampling frequency of $1250 \mathrm{~Hz}$. The accelerometer was calibrated before each test setting session using PCB calibrator with a signal of $9.8 \mathrm{~m} / \mathrm{s}^{2}$ and 159.2 Hz. Table 3 reports the characteristics. 
Table 3: Model, positioning and sensitivity of sampling devices.

\begin{tabular}{|l|l|c|}
\hline Model accelerometer & Position & $\begin{array}{c}\text { Sensitivity } \\
\left(\mathrm{mV} /\left(\mathrm{m} / \mathrm{s}^{2}\right)\right)\end{array}$ \\
\hline $\begin{array}{l}\text { Tri-axial accelerometer } \\
\text { SEN027-PCB }\end{array}$ & $\begin{array}{l}\text { On all vehicles the instrument is fixed on } \\
\text { the seat driver in exact point to which } \\
\text { corresponds the driver's sacroiliac joints } \\
\text { (his/her buttocks) }\end{array}$ & $\begin{array}{l}\text { X axis: } 10.52 \\
\text { Y axis: } 10.55 \\
\text { Z axis: } 10.88\end{array}$ \\
\hline $\begin{array}{l}\text { Uniaxial accelerometer } \\
\text { PCB 393A03 }\end{array}$ & $\begin{array}{l}\text { Axis sensitive in the vertical direction, } \\
\text { same direction of the Z axis the tri-axial } \\
\text { accelerometer (vertical axis). It was } \\
\text { fixed on the chassis on all vehicles at the } \\
\text { base of driver's seat. }\end{array}$ & Z axis: 10.55 \\
\hline
\end{tabular}

In this work, in order to get a representative WBV of the driver for total exposure duration of $8 \mathrm{~h}$ (daily vibration exposure), the WBV exposure for each operator was measured for a defined time representative of a standard cycle. The WBV was continuously measured at the driver seat pad under normal conditions for about $2.1 \mathrm{~h}$ for Dumper769 truck and $1.6 \mathrm{~h}$ for Mercedes model. The typical work cycle of haul trucks is: (1) loading (by a shovel or digger); (2) loaded travel; (3) dumping (unloading); and (4) unloaded travel. The cycle was repeated almost 35 times during the daily shift. The length of each work cycle varied between $10 \mathrm{~min}$ and 14 min and was dependent by different factors: (1) the variation of the loading point by the digger machine; (2) the dump zones, near or far by the shatter system; (3) loading waiting time; (4) time waiting during the travel for alternate passage of the trucks in some points due to the narrow road. Measurements obtained on each individual day were taken on haul trucks travelling the same route inside the quarry site. The lap belt was worn in all tests for the safety purpose.

"Dose" of vibration is based on specific relationships between the duration of exposure and vibration magnitude defined in the International Organisation of Standardisation (ISO) standards, allowing the daily vibration exposure to be re-expressed in terms of the equivalent acceleration that would impart the same energy over an $8 \mathrm{~h}$ reference period (a notional average working day). This is called the $\mathrm{A}(8)\left(\mathrm{m} / \mathrm{s}^{2}\right.$ r.m.s.). The ISO 2631-1 (1997) guidelines, specifically, indicates the way in order to assess the health risk from the vibration exposure. This guideline is applicable to the vibration in the frequency range from $0.5-80 \mathrm{~Hz}$, transmitted to the body as a whole through the seat pad. The vibration evaluation procedure incorporates a method of averaging vibration level over time and using third octave band frequency spectrum. The RMS acceleration of the frequency weighted vibration $\left(a_{w}\right)$ over a time period provides a measure of vibration level. It is defined by the equation:

$$
A(8)=a_{w} \sqrt{\frac{T_{\text {esp }}}{8}} \mathrm{~m} / \mathrm{s}^{2},
$$

where:

$A(8)$ is the daily dose expressed as $\left(\mathrm{m} / \mathrm{s}^{2}\right)$;

$T_{\text {exp }}$ is the exposure time expressed as (hour);

$a_{w}$ is the equivalent continuous RMS acceleration also expressed as $\left(\mathrm{m} / \mathrm{s}^{2}\right)$.

Individual RMS values of the accelerations measured by the precision vibration meter along the $\mathrm{x}, \mathrm{y}$, and $\mathrm{z}$ directions are represented by $a_{w x}, a_{w y}$, and $a_{w z}$ respectively. As the damage risk differs along the three axes, a multiplying factor is applied to the frequency 
weighted vibration values. In the case of $\mathrm{WBV}$, the acceleration values for the two lateral axes ( $x$ and $y$ ) are multiplied by 1.4, whereas for the vertical axis (z-axis) WBV values are multiplied

$$
a_{w}=\max \left(K_{x} * a_{w y}, K_{y} * a_{w y}, K_{z} * a_{w z}\right) \ldots
$$

where

$$
K_{x}=K_{y}=1.4 ; K_{z}=1 .
$$

These $\mathrm{K}$ factors are specific weighed coefficient and they are defined in order to consider the non-linearity of human response to different vibration frequencies during the exposure.

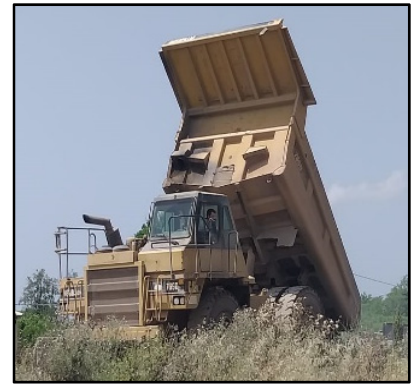

(a)

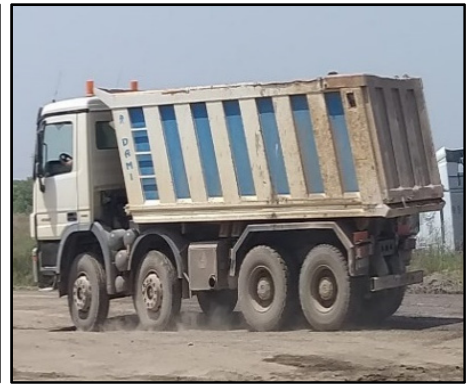

(b)

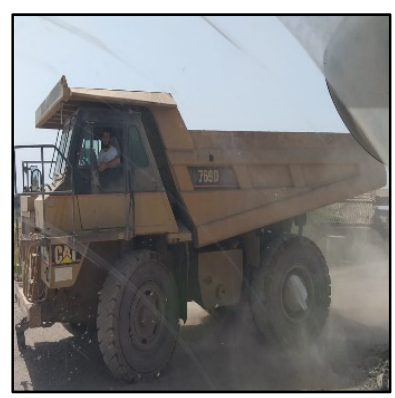

(c)

Figure 3: Overview of the LHD cycle. (a) The dumping of the material at the shutter system; (b) The loaded travel; and (c) The unloaded travel.

\section{RESULTS}

Accelerometer data were collected whilst the haul trucks were involved in normal daily work in a quarry site. The following pictures provides details of measurements realized on each vehicle. The $x$-axis indicates the time, expressed in second (s) while the $y$-axis shows the acceleration values $\left(\mathrm{m} / \mathrm{s}^{2}\right)$. Fig. 4 shows time history signal for the 769 model dumper while Fig. 5 shows it for the Mercedes model.

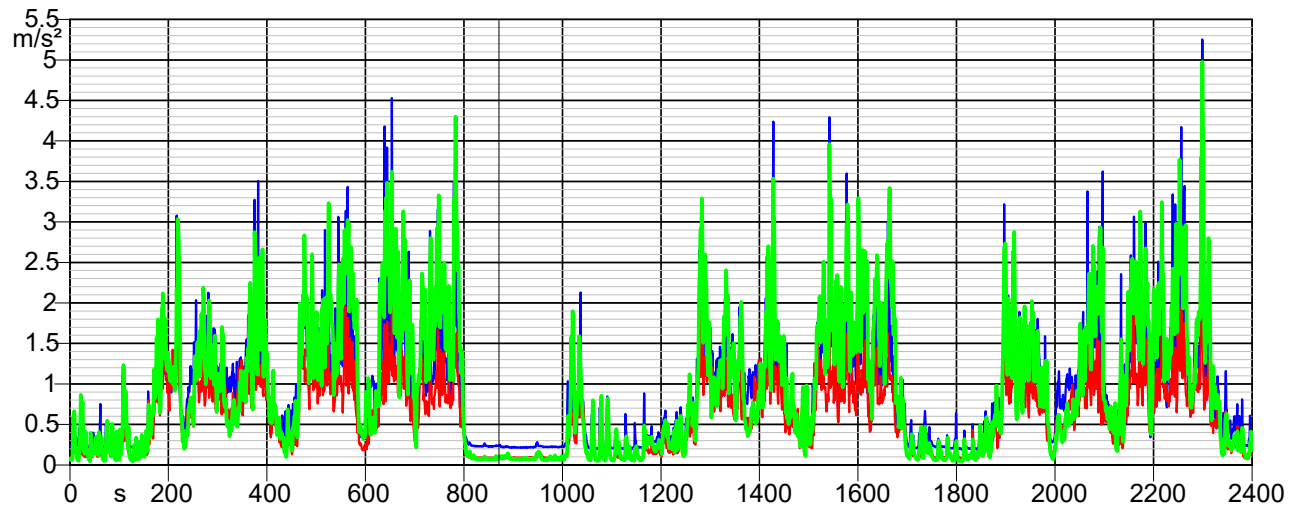

Figure 4: The trend line (blue $=x$ axis; red $=y$ axis; green $z=$ axis) of 769 dumper model. 


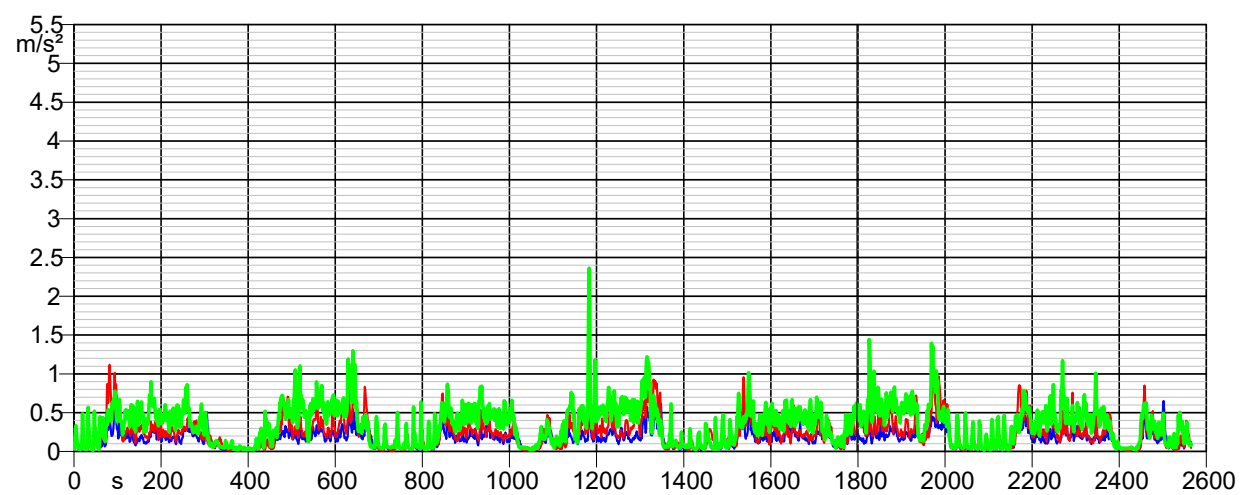

Figure 5: The time history (blue $=x$ axis; red $=y$ axis; green $=z$ axis) of Mercedes model .

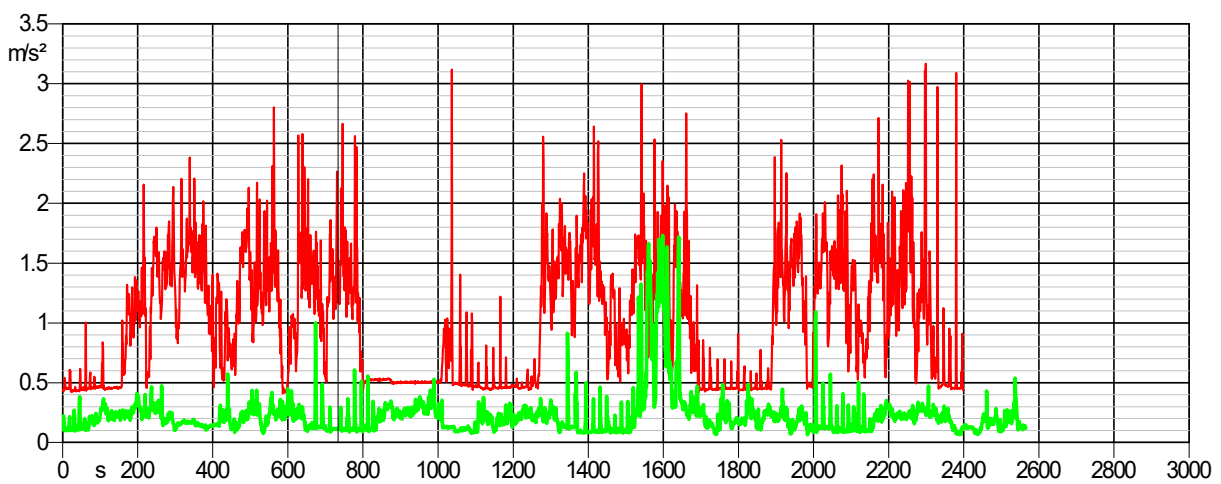

Figure 6: The vibration signal source of the 769 truck (red line) and Mercedes (green line).

The mean frequency-weighted r.m.s WBV of the measurements obtained from the driver's seat of mining haul trucks are presented in Figs 7 and 8. The data are reported in a third band octave. The colours indicates the directions as described above.

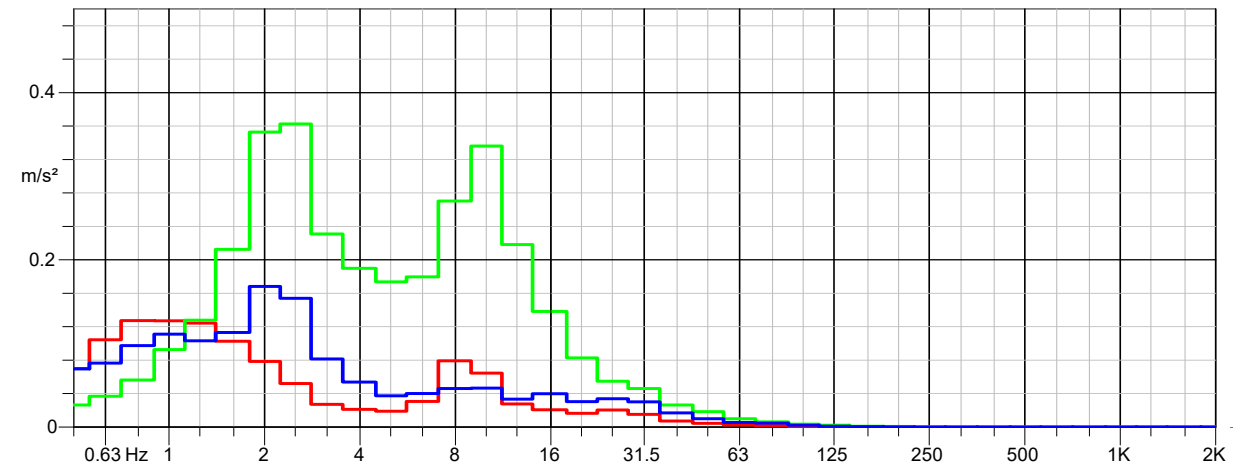

Figure 7: Frequency spectrum of the 769 dumper model. 


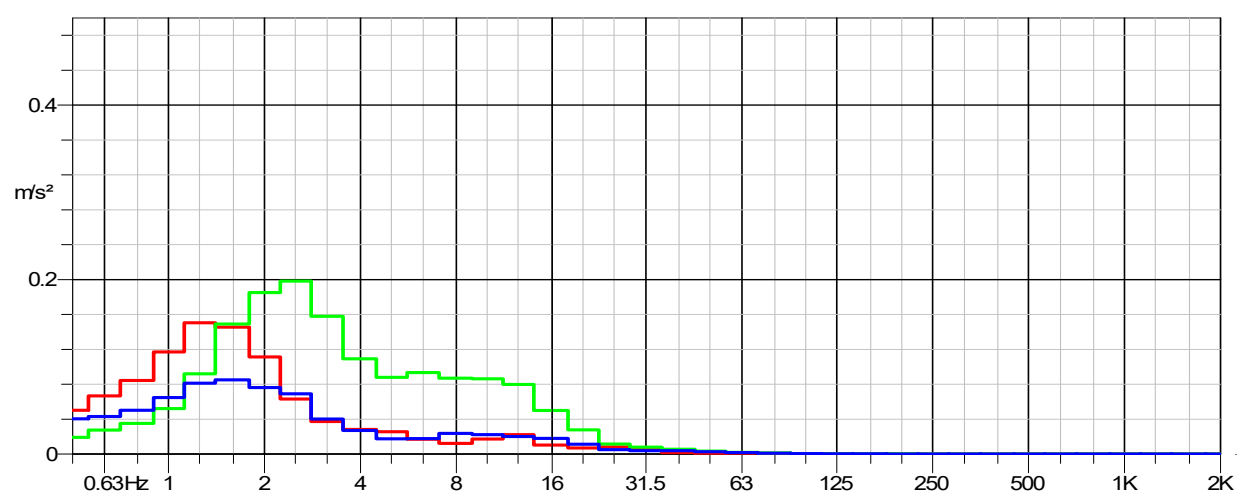

Figure 8: Frequency spectrum of the Mercedes model.

Fig. 9 compares the vibration signal source of the Mercedes vehicles (green line) and the 769 dumper (red line).

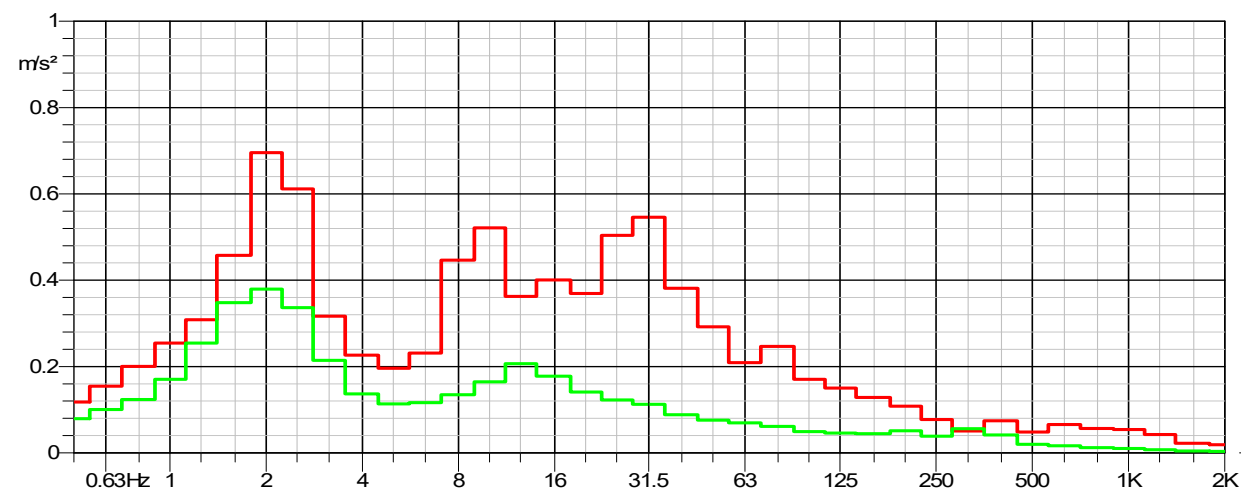

Figure 9: Frequency spectrum of signal source vibration for each vehicle.

As described above on each vehicle near the driver's seat in order a measurement was carried to characterize the signal source vibration. The graph above highlights that the trend of source signal vibration on 769 Caterpillar is similar to that of Mercedes model, with same relevant component at $2 \mathrm{~Hz}$ but shows higher values in all frequency spectrum and a relevant frequency component at $31.5 \mathrm{~Hz}$. Table 4 shows the data obtained.

Furthermore, for each measurement, the signal acquired on the driver's seat was analysed in order to evidence the max frequency along direction, the values of parameter $A(8)$ and the peak value. Table 5 sums up sampled values.

Table 4: Comparison of the frequencies and peak values.

\begin{tabular}{|l|c|c|}
\hline Model & $\mathrm{f}_{\max , \mathrm{z}}(\mathrm{Hz})$ & Peak $\left(\mathrm{m} / \mathrm{s}^{2}\right)$ \\
\hline Dumper 769 & 2 & 3.617 \\
\hline Mercedes & 2 & 1.731 \\
\hline
\end{tabular}


Table 5: Results for both models.

\begin{tabular}{|l|c|c|c|c|c|}
\hline Model & $\mathrm{f}_{\max , \mathrm{x}}(\mathrm{Hz})$ & $\mathrm{f}_{\max , \mathrm{y}}(\mathrm{Hz})$ & $\mathrm{f}_{\max , \mathrm{z}}(\mathrm{Hz})$ & $\mathrm{A}(8)\left(\mathrm{m} / \mathrm{s}^{2}\right)$ & Peak $\left(\mathrm{m} / \mathrm{s}^{2}\right)$ \\
\hline Dumper 769 & 2 & 1 & 10 & 0.498 & 4.973 \\
\hline Mercedes & 1.6 & 1.3 & 2.5 & 0.374 & 2.361 \\
\hline
\end{tabular}

\section{DISCUSSION}

A considerable difference in terms of acceleration values was observed in the signal source vibration. The higher vibration intensity is assessed on the Dumper 769 truck. This fact entails that this last model represents a higher vibrational source respect to the Mercedes truck and then the driver of the Dumper 769 suffers a higher daily dose exposure during his activities. Consequently comparing the $A(8)$ values for both vehicles, it is observed that daily exposure estimated according to ISO 2631-1:1997 on Dumper 769 model is much higher than that estimated on the Mercedes model. The $A(8)$ values are based on a 6 hour daily effective exposure. These values are taken into account on the basis of drivers' interview before the starting of measurement campaign. The analysis of sampled data highlights the vertical axis was predominantly associated with the highest frequency weighted accelerations in all measurements, which is consistent with previous investigations of mining haul trucks. The exposure along $x$ and $y$ axes results much lower. The graphs show that $y$ stress direction trend is similar for both trucks. The vibration stress on $x$ and $z$ directions appears always predominant on the 769 Dumper truck. The high acceleration values were recorded in the frequency range 1 and $10 \mathrm{~Hz}$ for $z$ axis, in the frequency range from $1-4 \mathrm{~Hz}$ along $x$ axis and between 1 and $2 \mathrm{~Hz}$ along $y$ axis. The predominant peak frequency weighted accelerations along the $z$ axis was $0.9 \mathrm{~m} / \mathrm{s}^{2}$ at $3.9 \mathrm{~Hz}$. The exposure level doesn't exceed the ISO 26311:1997 upper limit on both vehicles, highlighting that the drivers are exposed to caution zone with respect to potential health risks.

\section{CONCLUSIONS}

The aim of the current investigation is to highlight how different type of vibrational sources may generate a relevant variation of WBV exposure under the same boundary conditions. Nevertheless some common aspects may be underlined the most important of is that all drivers in quarry context are exposed to a very high total vibration magnitude along the vertical $z$ axis. On analysing the outcome of field tests, it may be observed that the same LHD operational cycle may generate a vibrational signal increasing with the weight of the machinery thus determining a difference in terms of daily dose greater than $30 \%$ between the two cases. This simple aspect allows some consideration about work organization. In particular quarry management, taking into account these occupational exposure data, is oriented to schedule workers' tasks also aiming to minimize $A(8)$. This target may be addressed by applying a simple FAST approach [24]. This last, well known as Functional Analysis Space (or Machine) Technique, takes into account the machineries necessary for the performance of the single activity together with their $a_{w}$ value. The formalization of this approach is defined by means of a matrix, which may be stated to represent the space-time discretization of the working task:

\begin{tabular}{|c|c|c|c|}
\hline & $\mathrm{T}_{1}$ & $\mathrm{~T}_{\mathrm{j}}$ & $\mathrm{T}_{\mathrm{n}}$ \\
\hline $\mathrm{M}_{1}$ & & & \\
\hline $\mathrm{M}_{\mathrm{i}}$ & & $\mathrm{a}_{\mathrm{w}}(\mathrm{i}, \mathrm{j})$ & \\
\hline $\mathrm{M}_{\mathrm{m}}$ & & & \\
\hline
\end{tabular}


The element of the matrix represents the equivalent continuous RMS acceleration of the $\mathrm{i}$-th machine in the interval $T_{j}=t_{j+1}-t_{j}$.

The worker's exposure to WBV is instead controlled by the indicating matrix $\left\{\mathrm{I}_{\mathrm{k}}(\mathrm{i}, \mathrm{j})\right\}$, whose element assumes the value of one if the k-th operator utilises the i-th machinery in the time interval $t_{j+1}-t_{j}$, otherwise it assumes a zero value. The exposure time associated with the $\mathrm{k}$-th operator is therefore:

$$
T_{E}(k)=T \sum_{i} \sum_{j} I_{k}(i, j) .
$$

Once $T_{e}(k)$ is assessed it may be inserted in eqn (1) and then the daily exposure is carried out. Such a method, with the outcome of field test allow to minimize exposure data without reducing quarrying productivity.

\section{ACKNOWLEDGEMENTS}

The authors wish to acknowledge the fundamental support received from the management, staff and workers of the Area Basalti srl whose full cooperation allowed the development of the research program.

\section{REFERENCES}

[1] Rehn, B. et al., Symptoms of musculoskeletal disorders among drivers of all-terrain vehicles in northern Sweden. NVWW, 36, pp. 13-18, 2005.

[2] Orsini, F., Rossi, A., Scorza, A., Botta, F. \& Sciuto, S.A., A comparison between a commercial WBV platform and an experimental prototype. 22nd IMEKO TC4 International Symposium and 20th International Workshop on ADC Modelling and Testing 2017: Supporting World Development Through Electrical and Electronic Measurements, pp. 154-158, 2017.

[3] Cardu, M., Lovera, E. \& Patrucco, M., Loading and haulage in quarries: Criteria for the selection of excavator-dumper system. Proceedings of the 14th International Symposium on Mine Planning and Equipment Selection, MPES 2005 and the 5th International Conference on Computer Applications in the Minerals Industries, CAMI, 2005.

[4] Monarca, D., Cecchini, M., Guerrieri, M., Santi, M., Bedini, R. \& Colantoni, A., Safety and health of workers: Exposure to dust, noise and vibrations. VII International Congress on Hazelnut, 845, pp. 437-442, 2008.

[5] Gerard, F. \& Pierre, M., Numerical assessment of fore-and-aft suspension performance to reduce whole-body vibration of wheel loader drivers. Journal of Sound and Vibration, 298, pp. 672-687, 2006.

[6] Alfaro Degan, G., Coltrinari, G., Lippiello, D. \& Pinzari, M., A comparison between methods for assessment of whole-body vibration exposure: a case study in a limestone quarry. International Journal of Safety and Security Engineering, 8(1), pp. 90-97, 2018.

[7] Bovenzi, M. \& Hulshof, C.T.J., An updated review of epidemiologic studies on the relationship between exposure to whole-body vibration and low back pain. J. Sound Vib., 215, pp. 595-611, 1998.

[8] Atkinson, S., Robb, M., Mansfiel, D. \& Neil, J., Long-term vibration dose for truck drivers: Preliminary results and methodological challenges. Proceedings of the 37th United Kingdom Conference on Human Responses to Vibration, 2002.

[9] Paddan, G.S., Mansfield, N.J., Arrowsmith, C.I., Rimell, A.N., King, S.K. \& Holmes, S.R., The influence of seat backrest angle on perceived discomfort during exposure to vertical whole-body vibration. Ergonomics, 55(8), pp. 923-936, 2012. 
[10] Kumar, S., Vibration in operating heavy haul trucks in overburden mining. Applied Ergonomics, 35(6), pp. 509-520, 2004.

[11] Bureau of Labor Statistics, Nonfatal Occupational Injuries and Illnesses Requiring Days Away from Work 2014, Bureau of Labor: Statistics, US Department of Labor, 2015.

[12] Scarlett, A.J. \& Stayner, R.M., Whole-body vibration on construction, mining and quarrying machines: Evaluation of emission and estimated exposure levels. HSE Report, 400, 2005.

[13] Alem, N., Application of the new ISO 2631-5 to health hazard assessment of repeated shocks in US army vehicles. Industrial Health, 43(3), pp. 403-412, 2005.

[14] Burgess-Limerick, R., How on earth moving equipment can ISO-2631 be used to evaluate WBV exposure? J. Safety Health Res. Pract., 4(2), pp. 13-21, 2012.

[15] Wolfgang, R. \& Burgess-Limerick, R., Whole-body vibration exposure of haul truck drivers at a surface coal mine. Applied Ergonomics, 45(6), pp. 1700-1704, 2014.

[16] Zhao, X. \& Schindler, C., Evaluation of whole-body vibration exposure experienced by operators of a compact wheel loader according to ISO 2631-1:1997 and ISO 26315:2004. International Journal of Industrial Ergonomics, 44(6), pp. 840-850, 2014.

[17] Smets, M.P.H., Eger, T.R. \& Greiner, S.G., Whole-body vibration experienced by haulage truck operators in surface mining operations: A comparison of various analysis methods utilized in the prediction of health risks. Appl. Ergon., 41(6), pp. 763-770, 2010.

[18] Chaudhary, D.K., Bhattacherjee, A., Patra, A.K. \& Chau, N., Whole-body vibration exposure of drill operators in iron ore mines and role of machine-related, individual, and rock-related factors. Safety and Health at Work, 6(4), pp. 268-278, 2015.

[19] Eger, T., Stevenson, J., Boileau, P.E., Salmoni, A. \& Vi, R.G., Predictions of health risks associated with the operation of load-haul-dump mining vehicles: Part 1 Analysis of whole-body vibration exposure using ISO 2631-1 and ISO-2631-5 standards. Int. J. Ind. Ergon., 38, pp. 726-738, 2008.

[20] Paddan, G.S. \& Griffin, M.J., Use of seating to control exposures to whole-body vibration. Health and Safety Executive, 2001.

[21] Yuming, Y., Subhash, R., Jue, Y.\& Boileau, P., Characterization of a hydro-pneumatic suspension strut with gas-oil emulsion. Mechanical Systems and Signal Processing, 106, pp. 319-333, 2018.

[22] Rehnberg, A. \& Drugge, L., Ride comfort simulation of a wheel loader with suspended axles. Int. J. Vehicle Syst. Model. Test., 3, pp. 168-188, 2008.

[23] Langer, T.H., Iversen, T.K., Andersen, N.K., Mouritsen, O.Ø. \& Hansen, M.R., Reducing whole-body vibration exposure in backhoe loaders by education of operators. Int. J. Ind. Ergon., 42, pp. 304-311, 2012.

[24] Alfaro Degan, G., Lippiello, D. \& Pinzari, M., A geostatistical approach to the functional analysis space technique: A case of study. Advances in Safety and Reliability: Proceedings of 16th European Safety and Reliability Conference (ESREL), 1, pp. 45-52, 2005. 